\title{
Acute pain responses in dairy calves undergoing cornual nerve blocks with or without topical anesthetic
}

\author{
Reyna E. Jimenez, Sarah J. J. Adcock, and Cassandra B. Tucker* \\ Center for Animal Welfare, Department of Animal Science, University of California, Davis 95616
}

\begin{abstract}
Dairy calves are routinely administered medicines, vaccines, and anesthesia via injection. Although injections are painful, little is known about methods to alleviate this pain. The aim of this study was to determine whether lidocaine-prilocaine cream, a topical anesthetic, reduced calves' pain response to a subcutaneous injection around the cornual nerve. Calves were assigned 1 of 2 treatments: lidocaine-prilocaine cream at the sites of injection $(\mathrm{n}=10)$ or no cream $(\mathrm{n}=9)$. Thirty minutes after treatment, calves received a subcutaneous injection of $2 \%$ buffered lidocaine hydrochloride around the left and right cornual nerves. Contrary to our hypothesis, calves that received anesthetic cream beforehand displayed more escape behaviors during the injections than control calves. Both treatments had similarly low amounts of head-related behaviors afterward. Maximum eye temperature did not differ between the calves that received anesthetic cream and control calves, although eye temperature increased over time for both treatments. Heart rate increased during the $30 \mathrm{~s}$ following the first injection in both treatments. There were no treatment differences for any heart rate measures over the 5-min period after the first injection (mean heart rate, root mean square of successive differences, high-frequency power, and the ratio of low-frequency power to high-frequency power). These results suggest that cornual nerve blocks with buffered lidocaine are painful and that a lidocaine-prilocaine cream was not only ineffective in reducing this pain but that it may also worsen it.

Key words: animal welfare, local anesthesia, injection, lidocaine-prilocaine cream
\end{abstract}

\section{INTRODUCTION}

Dairy cattle are routinely administered medicines, vaccines, and anesthesia via injection. Despite evidence

Received July 25, 2018.

Accepted December 10, 2018.

*Corresponding author: cbtucker@ucdavis.edu that injections are painful in humans (Gidudu et al., 2012), few studies have evaluated needle-related pain in farm animals. Ede et al. (2018) recently demonstrated that dairy calves find intramuscular injections in the rump aversive, but to date no studies have evaluated methods to alleviate injection pain in cattle.

Topical anesthetic is a well-established therapy for mitigating injection pain in humans (Taddio et al., 2015). A common topical anesthetic is lidocaine-prilocaine cream, an oil and water emulsion of $2.5 \%$ lidocaine and $2.5 \%$ prilocaine mixture in a $1: 1$ ratio by weight (Friedman et al., 2001). In humans, the cream is most effective when left in contact with the skin for 90 min (Bjerring and Arendt-Nielsen, 1990), but it can take effect within 5 to $10 \mathrm{~min}$ for fast-absorbing tissues such as the genital mucosa (Abbas et al., 2018). Treatment with lidocaine-prilocaine cream decreases pain in humans receiving vaccine injections (Friedman et al., 2001; Shah et al., 2015) and in dogs, cats, and rabbits undergoing venipuncture (Flecknell et al., 1990). However, in dairy calves, the cream was ineffective in numbing the skin around the horn bud, as confirmed by needle prick (Fierheller et al., 2012). Similarly, the cream did not reduce aversive responses to tail vein injections in mice (David et al., 2014) or rats (Flecknell et al., 1990).

Due to the apparent success of the lidocaine-prilocaine cream in decreasing injection pain in humans and the contradictory results in other species, our objective was to determine its efficacy in decreasing the acute pain response in dairy calves receiving a subcutaneous injection around the cornual nerve. Cornual nerve blocks are recommended practice to ensure local anesthesia during hot-iron disbudding, a painful husbandry procedure to prevent horn growth when the calf is less than 2 mo of age (Stock et al., 2013). Acute pain can be assessed noninvasively using behavioral measures, such as escape attempts and behaviors directed to the site of injury (Weary et al., 2006). In addition, acute pain can be identified noninvasively by physiological responses. Changes in eye temperature, reflecting alterations in peripheral blood flow due to activation of the sympathetic nervous system and hypothalamus- 
pituitary-adrenal axis, have been observed in response to painful procedures in calves (Stewart et al., 2010). Heart rate variability (HRV) can be used to detect relative changes in sympathetic and vagal activity, providing a more nuanced measure of pain than heart rate (HR) alone (Kovács et al., 2014). We hypothesized that calves that received lidocaine-prilocaine cream before injection would exhibit fewer escape behaviors, fewer head-related behaviors, lower maximum eye temperatures, and lower mean HR and higher HRV than control calves.

\section{MATERIALS AND METHODS}

The experiment was conducted at the University of California Davis Dairy Teaching and Research Facility from August to October 2017. The University of California Davis Institutional Animal Care and Use Committee approved all procedures and daily husbandry practices (protocol no. 19901).

\section{Animal Husbandry and Housing}

We used all female calves born on the farm between June 11 and September 17, 2017. Holstein $(\mathrm{n}=14)$ and Jersey $(\mathrm{n}=5)$ calves were housed individually in outdoor enclosures consisting of a plastic hutch $(2.0 \mathrm{~m}$ long $\times 1.5 \mathrm{~m}$ wide $)$ and wire-fenced pen $(2.0 \mathrm{~m}$ long $\times$ 1.5 wide $\times 0.9 \mathrm{~m}$ high $)$. Rice hull bedding $(\sim 15-20 \mathrm{~cm}$ deep) was used in each enclosure.

Calves were bottle fed $2.8 \mathrm{~L}$ of milk replacer $(26 \%$ CP, 16\% fat, 15\% TS; Calva Products Inc., Acampo, CA) at 930 and $1630 \mathrm{~h}$. Holstein and Jersey calves transitioned to bucket feeding at 35 or $38 \mathrm{~d}$ of age, respectively, and a dry TMR was introduced. At $50 \mathrm{~d}$ of age, feeding was reduced to 1 feeding in the morning. Water and starter $(18.3 \%$ CP, $2.8 \%$ fat, $4 \%$ crude fat; Associated Feed and Supply Co., Turlock, CA) were offered for ad libitum intake.

\section{Treatments}

Calves (mean age: $43 \mathrm{~d}$; range: 33-54 d) were assigned to 1 of 2 treatments, balanced by age and breed: lidocaine-prilocaine cream (Hi-Tech Pharmacal Co. Inc., Amityville, NY) applied at the sites of injections $(\mathrm{n}=10)$ or no cream (control; $\mathrm{n}=9)$. Calves were restrained in their home pen (Figure 1) and a $5-\mathrm{cm}^{2}$ area behind the lateral canthus of each eye was clipped using a 30-mm blade (model 9854-600, Wahl, Sterling, IL). One gram of cream was squeezed out of the tube onto the clipped area behind each eye. Using the end of the tube, the same person distributed the cream to form a layer approximately $3 \mathrm{~mm}$ deep. The calf was released after application of the cream. For control calves, the end of the closed tube was rubbed gently over the area but no cream was applied. Twenty-five minutes later, the calf was restrained again and fitted with an HR monitor (v800, Polar Electro Oy, Helsinki, Finland). Two minutes later, the cream was wiped off when all injection sites were disinfected with povidone-iodine scrub and alcohol. A 20-gauge $\times 25$-mm needle was used to administer a cornual nerve block on each side of the head. The block consisted of $5 \mathrm{~mL}$ of $2 \%$ lidocaine hydrochloride and $0.5 \mathrm{~mL}$ of $8.4 \%$ sodium bicarbonate if the calf was $\leq 40 \mathrm{~d}$ old or $6 \mathrm{~mL}$ of $2 \%$ lidocaine hydrochloride and $0.6 \mathrm{~mL}$ of $8.4 \%$ sodium bicarbonate if she was $>40 \mathrm{~d}$ old to account for the increase in BW with age. The number of calves in each age group was balanced across treatments $(\leq 40$-d-old anesthetic, $\mathrm{n}=$ 5 ; $\leq 40$-d-old control, $\mathrm{n}=4 ;>40$-d-old anesthetic, $\mathrm{n}$ $=5 ;>40$-d-old control, $\mathrm{n}=5$ ). Injections were given one after the other and were always given on the left side first. Each injection took $29 \pm 9 \mathrm{~s}$ (mean $\pm \mathrm{SD}$ ). One investigator, blind to the treatment, performed all injections. Calves remained in the head restraint for 5 min after the first injection to measure HRV. After release, we observed the calf's behavior in her home pen for $10 \mathrm{~min}$. Calves were disbudded with a heated iron immediately after data collection for this experiment was finished. All data collection occurred before the morning feeding.

\section{Dependent Variables}

Behavior. We recorded calf behavior with 3 cameras (2 HC-V180 and 1 HC-V550, Panasonic, Kadoma, Japan) on tripods. A camera was positioned along each side of the pen approximately $60 \mathrm{~cm}$ in front of the calf's eye. A third camera was positioned approximately 120 $\mathrm{cm}$ in front of the pen. Video recordings were scored for behavioral responses beginning when the needle was inserted and ending when the needle was removed for each injection (struggling, hind leg side step, foreleg lift, eye widening) and for a 10-min period after the calf was released (head scratch, head rub, head shake, buck/jump/kick, lying; all definitions in Table 1). Behaviors were chosen based on our preliminary observations of calves' responses during cornual nerve blocks in the head restraint and what could be reliably assessed from video.

The same observer, blind to treatment, analyzed all videos using Behavioral Observation Research Interactive Software (BORIS; Friard and Gamba, 2016). All measures had high intraobserver reliability (5 calves; intraclass correlation coefficient: $\geq 0.88$ ).

$H R$ and $H R V$. We recorded continuous interbeat intervals while the calf was restrained. The HR monitor 
Table 1. Ethogram used to evaluate the behavioral differences between calves that had a topical anesthetic applied before injection and those that did not

\begin{tabular}{|c|c|c|}
\hline Behavior & Definition & Camera angle \\
\hline Eye widening & $\begin{array}{l}\text { White of the eye is visible. A new bout begins when eye white is not visible } \\
\text { for }>1 \mathrm{~s} \text {. }\end{array}$ & $\begin{array}{l}\text { Left eye analyzed when injection was } \\
\text { given on right and vice versa }\end{array}$ \\
\hline Foreleg lift & $\begin{array}{l}\text { Any part of the foreleg is in an upward motion. A new bout begins when the } \\
\text { foreleg moves down. }\end{array}$ & Front \\
\hline Hindleg side step & Base of the calf's tail crosses into a quadrant. ${ }^{1}$ & Front \\
\hline Head rub & $\begin{array}{l}\text { Back and forth movement of the head on any object. A new bout begins if } \\
\text { head does not move against the object for }>2 \mathrm{~s} \text {. }\end{array}$ & Front \\
\hline Head shake & $\begin{array}{l}\text { Head moves right and left at least once in a successive rapid motion. There } \\
\text { must be } 1 \mathrm{~s} \text { between successive rapid side-to-side movements to count as a } \\
\text { new head shake. }\end{array}$ & Front \\
\hline Lying & Belly or side touching the ground. & Front \\
\hline Buck/jump/kick & $\begin{array}{l}\text { Both hind legs or both forelegs are lifted off the ground or } 1 \text { hind leg is lifted } \\
\text { off the ground and extended away from the body. }\end{array}$ & Front \\
\hline
\end{tabular}

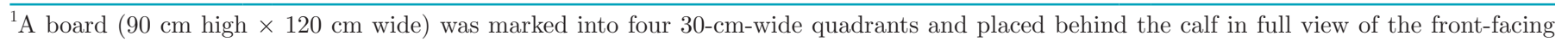
camera.

consisted of an electrode belt that transmitted data to the recording watch through Bluetooth Smart wireless technology. After clipping a strip behind the left forelimb, the belt was fastened around the calf's thorax. Ultrasound transmission gel and water were applied to the electrode contact sites and the belt was secured with bandage wrap (Co-Flex, Andover Coated Prod- ucts Inc., Salisbury, MA). The HR monitor remained on the calves until data collection was finished. Data were downloaded using Polar software (FlowSync, version 2.3.8, Polar Electro Oy).

We performed HRV analysis using Kubios HRV 3.03 software (Tarvainen et al., 2014). Time-domain measures included mean HR (beats/min) and root mean

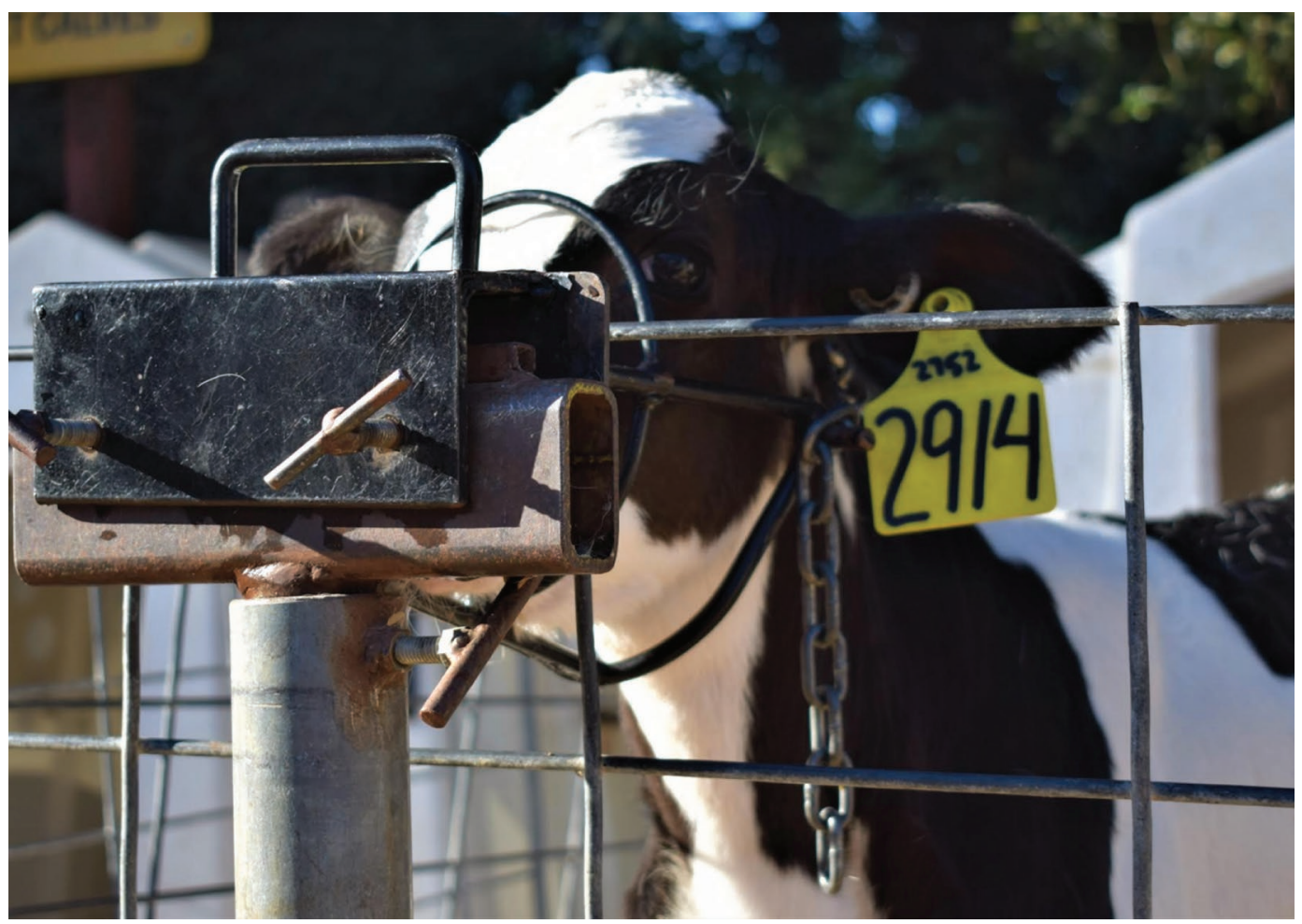

Figure 1. Method of restraining dairy calves for treatment application and injections. 
square of successive differences (RMSSD). Frequencydomain measures included high-frequency power $(0.30$ $0.80 \mathrm{~Hz}$ ) and the low frequency:high frequency ratio. The threshold between low and high frequencies was chosen based on previous HRV studies in calves (reviewed in Kovács et al., 2014). We examined the 5-min period following the first injection, which included the second injection, using fast Fourier transformation (von Borell et al., 2007). Frequency-domain measures were reported in normalized units. Artifacts (e.g., ectopic heartbeats) were identified using the program's "very low" threshold setting to minimize distortion of natural variation in HR and corrected with a cubic spline interpolation. An average error rate of $6 \%$ was accepted, and 1 calf from each treatment was removed due to error rates exceeding this threshold. In addition, 1 control calf was excluded from the analysis due to equipment failure.

Eye Temperature. An infrared thermal camera (T430, Flir Systems Inc., Wilsonville, OR) was used to photograph each eye at a distance of $0.5 \mathrm{~m}$. One photograph was taken during each of 3 time intervals relative to the first injection ( -2 to 0,1 to 4 , and 4 to $7 \mathrm{~min}$ ). The maximum temperature $\left({ }^{\circ} \mathrm{C}\right)$ of the medial posterior palpebral border of the lower eyelid and the lacrimal caruncle was determined using image analysis software (ResearchIR Max, Flir Systems Inc.; intraobserver reliability of 10 calves: intraclass correlation coefficient: $0.98)$. Due to equipment failure, $15 \%$ of thermal photos were missed, which occurred equally across treatments and time intervals. Data collection took place during morning hours, when there was no direct sunlight toward the camera.

\section{Statistical Analysis}

Eye widening, lying, and bucks/jumps/kicks were too rare to warrant statistical comparisons. The counts of foreleg lifts, hind leg side steps, and struggling were summed as a single measure of escape behavior because they often occurred together and incidences of each individual behavior were rare in some calves (Supplemental Table S1, https://doi.org/10.3168/jds .2018-15445). Head shaking, rubbing, and scratching were summed into a single measure of head-related behaviors due to low counts of each individual behavior (Supplemental Table S1).

All analyses were conducted in $\mathrm{R}$ version 3.4.1 ( $\mathrm{R}$ Core Team, 2017). The effect of treatment on escape behavior was analyzed using a generalized linear model with a Poisson distribution. We modeled treatment effects on head-related behaviors with a generalized linear model with a log-link quasi-Poisson distribution. We used a linear mixed model to determine the effects of treatment, time interval (3 categories), and their interaction on eye temperature, with calf fitted as the random effect. For HRV analysis, we tested for a treatment effect on time- and frequency-domain measures using linear models. In addition, we compared mean HR over a 30-s period after the first injection with baseline (30 s before injection) using a linear mixed model with calf as a random effect. For all models, residuals versus fits plots and quantile-quantile $(\mathrm{Q}-\mathrm{Q})$ plots were visually inspected to confirm homogeneous variance and normality of residuals, respectively. Behavioral models were fitted with the $g l m$ function in base R, and models for eye temperature and HR were fitted with the lme function in package nlme (Pinheiro et al., 2017). Degrees of freedom were estimated using the containment method. No correlation structure was used. Differences were considered significant at $P \leq$ 0.05 .

\section{RESULTS}

\section{Behavior}

Calves treated with an anesthetic cream displayed more escape behaviors during injections than control calves (Table 2; for information about each individual behavior, see Supplemental Table S1, https://doi.org/ 10.3168/jds.2018-15445). However, both treatments had similarly low amounts of head-related behaviors after release (Table 2; for information about each individual behavior, see Supplemental Table S1). For both treatments, eye widening was rare (median count: 1; interquartile range: 2.5 ). We observed only 2 calves lying down, 1 in each treatment. Bucks/jumps/kicks never occurred.

\section{Eye Temperature}

We found no differences in eye temperature between the calves that received anesthetic cream and the control calves $\left(F_{1,16}=0.60 ; P=0.450\right)$, although temperature increased over time $\left(F_{2,67}=6.33 ; P=0.003\right.$; Figure 2). No interaction between time interval and treatment was found $\left(F_{2,67}=0.34 ; P=0.710\right)$.

\section{$H R$ and HRV}

Heart rate increased from baseline during the $30 \mathrm{~s}$ that followed the first injection $\left(F_{1,17}=24.73 ; P<\right.$ $0.001)$ regardless of treatment $\left(F_{1,17}=0.37 ; P=0.550\right.$; Figure 3 ). We did not observe differences between the control calves and those that received anesthetic cream for any HRV measure (Table 2). 


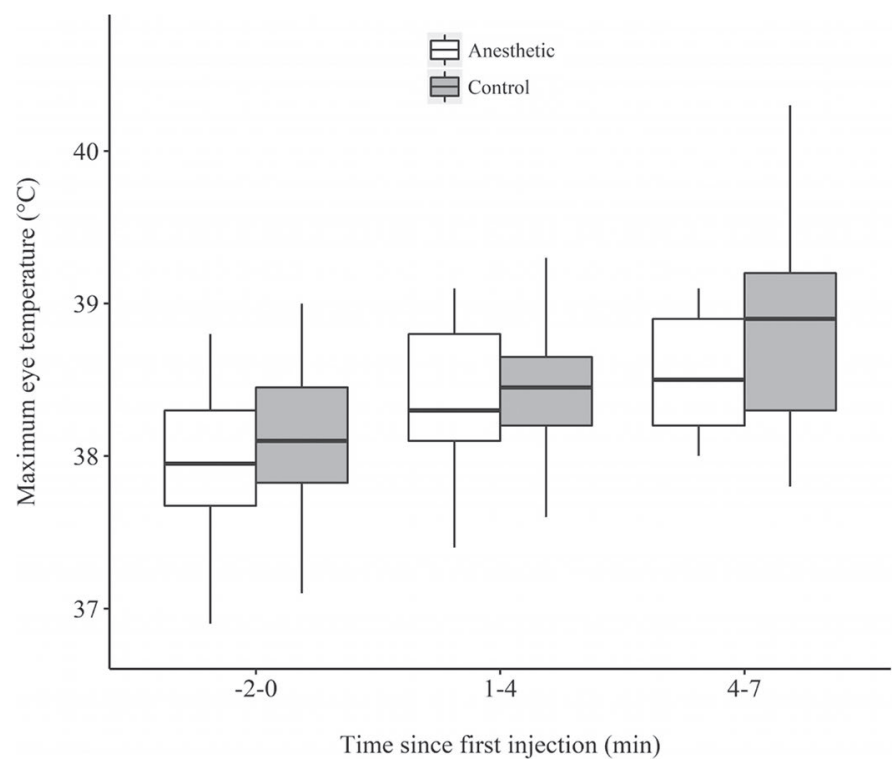

Figure 2. Maximum eye temperature over 3 time intervals relative to the first injection of cornual nerve block of buffered lidocaine. Calves had a topical anesthetic applied beforehand or not (control). Whiskers indicate the second and 98th percentiles. The top and bottom of the boxes indicate the 75 th and 25 th quartiles, respectively.

\section{DISCUSSION}

The application of a lidocaine-prilocaine cream before painful procedures has been shown to diminish pain responses in humans (e.g., Abbas et al., 2018; Yin and Jiang, 2018) but has mixed results in other species (Flecknell et al., 1990; Fierheller et al., 2012; David et al., 2014). Our results indicate that lidocaine-prilocaine cream was not only ineffective in reducing injection pain in dairy calves but was possibly aversive. Calves that received anesthetic cream displayed more escape behaviors during injections than controls. We did not observe differences in head-related behaviors, eye tem-

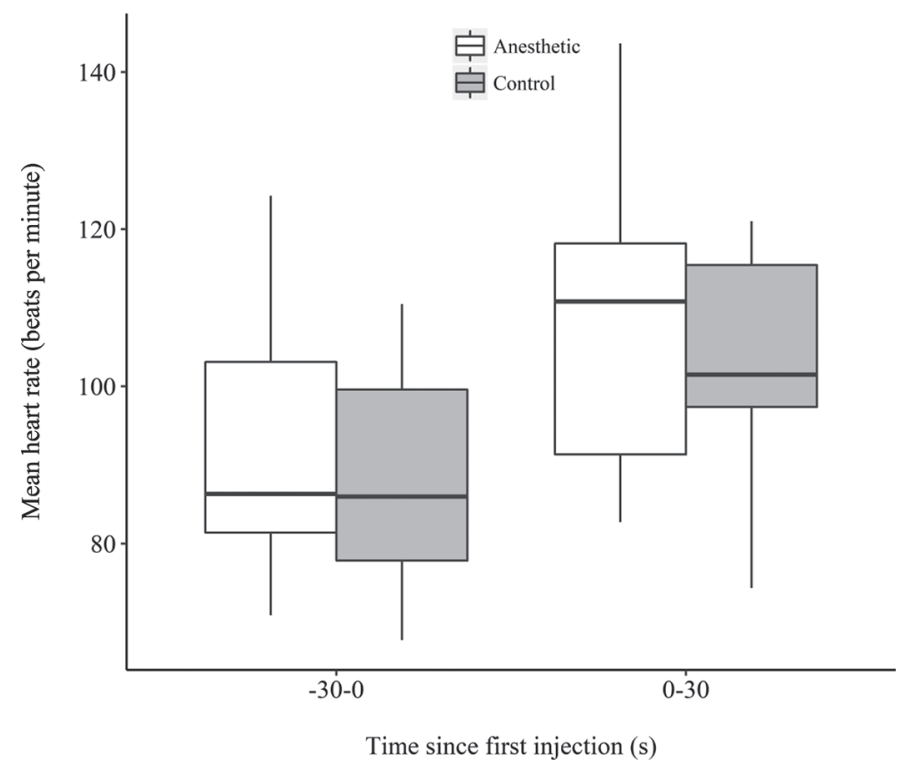

Figure 3. Mean heart rate $30 \mathrm{~s}$ before and $30 \mathrm{~s}$ after the first injection of a cornual nerve block of buffered lidocaine. Calves had a topical anesthetic applied beforehand or not (control). Whiskers indicate the second and 98th percentiles. The top and bottom of the boxes indicate the 75 th and 25 th quartiles, respectively.

perature, and HRV after injection between anesthetic and control calves.

Although lidocaine-prilocaine cream has been shown to decrease pain responses in rabbits during tattooing (Keating et al., 2012) and in dogs, cats, and rabbits undergoing venipuncture (Flecknell et al., 1990), our study suggested that the topical anesthetic was aversive for dairy calves undergoing a cornual nerve block. The aversive effects could possibly be explained by inflammation associated with lidocaine-prilocaine cream. In rats, wounds treated with lidocaine-prilocaine cream tended to be more inflamed than those infiltrated with lidocaine (Nykanen et al., 1991). Increased inflamma-

Table 2. Behavioral and heart rate (HR) measures (LSM \pm SE) in calves with a topical anesthetic applied before cornual nerve blocks or no anesthetic (control) ${ }^{1}$

\begin{tabular}{lcccc}
\hline & \multicolumn{2}{c}{ Treatment } & & \\
\cline { 2 - 3 } Measure $^{2}$ & Control & Anesthetic & Test statistic & $P$-value \\
\hline Behavior & & & & \\
$\quad$ Escape (no./both injections) & $11.3 \pm 1.1$ & $15.4 \pm 1.2$ & $\mathrm{z}=2.40$ & 0.016 \\
$\quad$ Head related (no./10 min) & $2.7 \pm 0.7$ & $1.9 \pm 0.6$ & $\mathrm{t}=-0.80$ & 0.425 \\
Heart rate & & & & \\
$\quad$ Mean heart rate (beats/min) & $94.0 \pm 5.7$ & $90.6 \pm 5.1$ & $F_{1,14}=0.20$ & 0.661 \\
RMSSD (ms) & $116.6 \pm 15.8$ & $100.0 \pm 13.9$ & $F_{1,14}=0.62$ & 0.444 \\
HF (normalized) & $33.0 \pm 5.4$ & $46.0 \pm 4.8$ & $F_{1,14}=3.21$ & 0.095 \\
LF:HF & $2.6 \pm 0.6$ & $1.5 \pm 0.5$ & $F_{1,14}=1.91$ & 0.189 \\
\hline
\end{tabular}

${ }^{1}$ Escape behaviors were scored during the time of the injections, and head-related behaviors were scored during the 10 -min period afterward.

${ }^{2} \mathrm{RMSSD}=$ root mean square of successive differences; HF = high frequency; LF:HF = low frequency:high frequency ratio. 
tion was also seen in guinea pigs that had open wounds treated with lidocaine-prilocaine cream compared with untreated wounds (Powell et al., 1991). In another study, 4 out of 11 mares developed mild to moderate swelling approximately $20 \mathrm{~min}$ after lidocaine-prilocaine cream was applied to the labia, with 1 mare showing reddening of the treated skin (Erkert et al., 2005). Redness (i.e., erythema) has also been reported in humans after an application time of 30 min (Buckley and Benfield, 1993). In a previous study, 2 out of 31 human patients treated with lidocaine-prilocaine cream for the relief of cannulation pain stopped their treatment due to recurring local irritation after application (Wehle et al., 1989). We did not quantify swelling and redness in the current study and only speculate that inflammation could be responsible for the cream's aversive effects.

The efficacy of lidocaine-prilocaine cream has been linked to the duration of application. It is recommended that lidocaine-prilocaine cream be applied for at least 1 $\mathrm{h}$ before needle insertion (Buckley and Benfield, 1993), but other studies have shown its efficacy as early as 20 min when applied in a rabbit's pinna before tattooing and $30 \mathrm{~min}$ in children with atopic dermatitis if the cream is applied under an occlusive dressing (Rönnerfält et al., 1998; Keating et al., 2012). However, another study found that lidocaine-prilocaine cream did not eliminate responses to needle pricks around the horn bud of dairy calves after a 90-min application, which the authors suggested was due to the thickness of the skin preventing subcutaneous absorption (Fierheller et al., 2012). The aversive response we observed in our study suggests that the cream was absorbed to some extent. However, the absorption is likely fairly superficial, as $5 \mathrm{~mm}$ is the maximum depth of analgesia reported for lidocaine-prilocaine cream in humans (Bjerring and Arendt-Nielsen, 1990). A cornual nerve block is typically administered with a $25-\mathrm{mm}$ needle, as we did in the current study, and absorption of the cream to this depth is unlikely.

Head-related behaviors (shaking, scratching, and rubbing) were rare in both treated and control calves during the 10-min period following restraint. The low occurrence of this behavior may be due to the anesthesia from the lidocaine, which sets in about $2 \mathrm{~min}$ after the injection (Fierheller et al., 2012). Head-related behaviors would likely be more useful to monitor during the injection; however, this was not possible in the current study as the calf was restrained.

Maximum eye temperature increased by $0.55^{\circ} \mathrm{C}$ after injection regardless of treatment, consistent with the expectation that cornual nerve blocks are painful. Stewart et al. (2008) found a lower, albeit still statistically significant, increase of $0.19^{\circ} \mathrm{C}$ in eye temperature following a cornual nerve block in dairy calves. An increase in eye temperature has also been observed 5 to $10 \mathrm{~min}$ after aversive procedures such as hair clipping in horses (Yarnell et al., 2013), claw trimming in cows (Gómez et al., 2018), and hot-iron disbudding and surgical castration in calves (Stewart et al., 2008, 2010). Although the mechanism for this increase in eye temperature is unclear, it is believed that the response is associated with vasodilation mediated by the autonomic nervous system and vasodilators released in response to pain (Stewart et al., 2010). However, we cannot rule out that the increase in eye temperature could be due, at least in part, to the vasodilatory effects of the lidocaine, particularly because it was administered in close proximity to the eye (Newton et al., 2007).

Mean HR increased in the $30 \mathrm{~s}$ after the first injection compared with baseline for both treatments. Heart rate was found to be a useful tool for evaluating pain in dairy calves undergoing surgical castration or hotiron disbudding (Stewart et al., 2008, 2009, 2010). We observed an increase of 14 beats/min in dairy calves receiving injections, similar to the 15 beats/min change observed in calves undergoing surgical castration without anesthesia (Stewart et al., 2010) but less than the 35 beats/min increase caused by disbudding without anesthesia (Stewart et al., 2008). This increase in HR is consistent with the expectation that cornual nerve blocks are painful.

We did not observe treatment differences in HRV during the 5-min period following the first injection. We expected to see lower HRV in the control calves given no anesthetic, which would indicate increased levels of autonomic stimulation, a sign of acute pain (Kovács et al., 2014). Reduced vagal tone, a marker of stress, can be measured as the decrease in the time domain HRV parameter, RMSSD, and in the frequency domain parameter, the high-frequency power (McLaughlin et al., 2015). We also expected to see an increase in low frequency:high frequency ratio, suggesting sympathetic dominance, which is seen in painful situations such as hot-iron disbudding without local anesthesia (Stewart et al., 2008). However, the lack of observable change in our study may be related to the injections being less painful than manipulations used in this previous work. For example, compared with calves 5 -min postdisbudding (Stewart et al., 2008), our calves had a lower HR (92 vs. 129 beats/min), higher RMSSD (108 vs. 41 $\mathrm{ms}$ ), higher high frequency (40 vs. 16), and lower low frequency:high frequency ratio (2.0 vs. 6.2$)$.

Given that the lidocaine-prilocaine cream was ineffective in reducing pain responses during injection, other forms of pain relief should be investigated. A topical anesthetic containing short-acting lidocaine and long-acting bupivacaine reduced short-term pain sensitivity in calves after scoop dehorning and surgical 
castration (Espinoza et al., 2013; Lomax and Windsor, 2013). There is also the possibility of using nonpharmacological alternatives to reduce pain in dairy calves. For example, it is well documented that distractions during painful procedures can exert analgesic effects (Villemure and Bushnell, 2002). Providing calves with an oral insert (e.g., teat) during the time of injection may serve as a distraction and decrease pain responses. Steers struggled less when provided an oral insert during restraint compared with controls (Aitken et al., 2013). In addition, children undergoing immunization displayed fewer distress behaviors when distractions were used compared with topical anesthetic (Cohen et al., 1999).

In conclusion, a 30-min application of lidocaine-prilocaine cream did not reduce responses to cornual nerve block injections of buffered lidocaine in dairy calves and may even have been aversive. In addition, the increase in mean HR and maximum eye temperature after injection is consistent with responses to other painful procedures, providing support that cornual nerve blocks are painful.

\section{ACKNOWLEDGMENTS}

We thank University of California (UC) Davis Dairy Facility manager Doug Gisi, assistant manager Maria Patino, and the dairy interns for animal care and support. We are grateful to Chela Owens (UC Davis) for assisting with data collection. This study was supported by USDA (Washington, DC) Multistate Research Project NC1029. We gratefully acknowledge the infrastructure support of the UC Davis Department of Animal Science, College of Agricultural and Environmental Sciences and the UC Davis California Agricultural Experiment Station.

\section{REFERENCES}

Abbas, A. M., H. A. Abdel Hafiz, A. M. Abdelhafez, A. Michael, and A. M. Ismail. 2018. Topical lidocaine-prilocaine cream versus lidocaine infiltration for pain relief during repair of perineal tears after vaginal delivery: Randomized clinical trial. J. Matern. Fetal Neonatal Med. https://doi.org/10.1080/14767058.2018.1428304.

Aitken, B. L., J. M. Stookey, S. Noble, J. Watts, and D. Finlay. 2013. The effects of an oral distraction on cattle during a painful procedure. Can. Vet. J. 54:588-590.

Bjerring, P., and L. Arendt-Nielsen. 1990. Depth and duration of skin analgesia to needle insertion after topical application of EMLA cream. Br. J. Anaesth. 64:173-177. https://doi.org/10.1093/bja/ 64.2.173.

Buckley, M. M., and P. Benfield. 1993. Eutectic lidocaine/prilocaine cream. Drugs 46:126-151. https://doi.org/10.2165/00003495 -199346010-00008.

Cohen, L. L., R. L. Blount, R. J. Cohen, E. R. Schaen, and J. F. Zaff. 1999. Comparative study of distraction versus topical anesthesia for pediatric pain management during immunizations. Health Psychol. 18:591-598. https://doi.org/10.1037/0278-6133.18.6.591.
David, J. M., S. Duarte Vogel, K. Longo, D. Sanchez, and G. Lawson. 2014. The use of eutectic mixture of lidocaine and prilocaine in mice (Mus musculus) for tail vein injections. Vet. Anaesth. Analg. 41:654-659. https://doi.org/10.1111/vaa.12177.

Ede, T., M. A. G. von Keyserlingk, and D. M. Weary. 2018. Approachaversion in calves following injections. Sci. Rep. 8:9443. https://doi .org/10.1038/s41598-018-27669-7.

Erkert, R. S., C. G. Macallister, G. Campbell, M. E. Payton, R. Shawley, and C. R. Clarke. 2005. Comparison of topical lidocaine/prilocaine anesthetic cream and local infiltration of $2 \%$ lidocaine for episioplasty in mares. J. Vet. Pharmacol. Ther. 28:299-304. https: //doi.org/10.1111/j.1365-2885.2005.00657.x.

Espinoza, C., S. Lomax, and P. Windsor. 2013. The effect of a topical anesthetic on the sensitivity of calf dehorning wounds. J. Dairy Sci. 96:2894-2902. https://doi.org/10.3168/jds.2012-5954.

Fierheller, E. E., N. A. Caulkett, D. B. Haley, D. Florence, and L. Doepel. 2012. Onset, duration and efficacy of four methods of local anesthesia of the horn bud in calves. Vet. Anaesth. Analg. 39:431-435. https://doi.org/10.1111/j.1467-2995.2012.00717.x.

Flecknell, P. A., J. H. Liles, and H. A. Williamson. 1990. The use of lignocaine-prilocaine local anaesthetic cream for pain-free venepuncture in laboratory animals. Lab. Anim. 24:142-146. https:// doi.org/10.1258/002367790780890121.

Friard, O., and M. Gamba. 2016. BORIS: A free, versatile open-source event-logging software for video/audio coding and live observations. Methods Ecol. Evol. 7:1325-1330. https://doi.org/10.1111/ 2041-210X.12584.

Friedman, P. M., E. A. Mafong, E. S. Friedman, and R. G. Geronemus. 2001. Topical anesthetics update: EMLA and beyond. Dermatol. Surg. 27:1019-1026.

Gidudu, J. F., G. A. Walco, A. Taddio, W. T. Zempsky, S. A. Halperin, A. Calugar, N. A. Gibbs, R. Hennig, M. Jovancevic, E. Netterlid, T. O'Connor, J. M. Oleske, F. Varricchio, T. F. Tsai, H. Seifert, and A. E. Schuind. 2012. Immunization site pain: Case definition and guidelines for collection, analysis, and presentation of immunization safety data. Vaccine 30:4558-4577. https://doi .org/10.1016/j.vaccine.2012.03.085.

Gómez, Y., R. Bieler, A. K. Hankele, M. Zähner, P. Savary, and E. Hillmann. 2018. Evaluation of visible eye white and maximum eye temperature as non-invasive indicators of stress in dairy cows. Appl. Anim. Behav. Sci. 198:1-8. https://doi.org/10.1016/j .applanim.2017.10.001.

Keating, S. C., A. A. Thomas, P. A. Flecknell, and M. C. Leach. 2012. Evaluation of EMLA cream for preventing pain during tattooing of rabbits: Changes in physiological, behavioural and facial expression responses. PLoS One 7:e44437. https://doi.org/10.1371/ journal.pone.0044437.

Kovács, L., V. Jurkovich, M. Bakony, O. Szenci, P. Poti, and J. Tozser. 2014. Welfare implication of measuring heart rate and heart rate variability in dairy cattle: Literature review and conclusions for future research. Animal 8:316-330. https://doi.org/10.1017/ S1751731113002140.

Lomax, S., and P. A. Windsor. 2013. Topical anesthesia mitigates the pain of castration in beef calves. J. Anim. Sci. 91:4945-4952. https: //doi.org/10.2527/jas.2012-5984.

McLaughlin, K. A., L. Rith-Najarian, M. A. Dirks, and M. A. Sheridan. 2015. Low vagal tone magnifies the association between psychosocial stress exposure and internalizing psychopathology in adolescents. J. Clin. Child Adolesc. Psychol. 44:314-328. https:// doi.org/10.1080/15374416.2013.843464.

Newton, D. J., G. A. McLeod, F. Khan, and J. J. F. Belch. 2007. Mechanisms influencing the vasoactive effects of lidocaine in human skin. Anaesthesia 62:146-150. https://doi.org/10.1111/j.1365 $-2044.2006 .04901 . x$.

Nykanen, D., N. Kissoon, M. Rieder, and R. Armstrong. 1991. Comparison of topical mixture of lidocaine and prilocaine (EMLA) versus $1 \%$ lidocaine infiltration on wound healing. Pediatr. Emerg. Care 7:15-17. https://doi.org/10.1097/00006565-199102000-00004.

Pinheiro, J., D. Bates, S. DebRoy, D. Sarkar, and R Core Team. 2017. nlme: Linear and nonlinear mixed effects models. $\mathrm{R}$ package ver- 
sion 3.1-131. Accessed Oct. 31, 2017. http://CRAN.R-project.org/ package $=$ nlme.

Powell, D. M., G. T. Rodeheaver, P. A. Foresman, C. L. Hankins, K. T. Bellian, C. A. Zimmer, D. G. Becker, and R. F. Edlich. 1991. Damage to tissue defenses by EMLA cream. J. Emerg. Med. 9:205-209. https://doi.org/10.1016/0736-4679(91)90414-b.

R Core Team. 2017. R: A Language and Environment for Statistical Computing. R Foundation for Statistical Computing, Vienna, Austria.

Rönnerfält, L., J. Fransson, and C. Wahlgren. 1998. EMLA cream provides rapid pain relief for the curettage of molluscum contagiosum in children with atopic dermatitis without causing serious application-site reactions. Pediatr. Dermatol. 15:309-312. https:// doi.org/10.1111/j.1525-1470.1998.tb01347.x.

Shah, V., A. Taddio, C. M. McMurtry, S. A. Halperin, M. Noel, R. Pillai Riddell, C. T. Chambers, and H. E. Team. 2015. Pharmacological and combined interventions to reduce vaccine injection pain in children and adults: Systematic review and meta-analysis. Clin. J. Pain 31:S38-S63. https://doi.org/10.1097/AJP.0000000000000281.

Stewart, M., K. J. Stafford, S. K. Dowling, A. L. Schaefer, and J. R. Webster. 2008. Eye temperature and heart rate variability of calves disbudded with or without local anaesthetic. Physiol. Behav. 93:789-797. https://doi.org/10.1016/j.physbeh.2007.11.044.

Stewart, M., J. M. Stookey, K. J. Stafford, C. B. Tucker, A. R. Rogers, S. K. Dowling, G. A. Verkerk, A. L. Schaefer, and J. R. Webster. 2009. Effects of local anesthetic and a nonsteroidal antiinflammatory drug on pain responses of dairy calves to hot-iron dehorning. J. Dairy Sci. 92:1512-1519. https://doi.org/10.3168/jds.2008-1578.

Stewart, M., G. A. Verkerk, K. J. Stafford, A. L. Schaefer, and J. R. Webster. 2010. Noninvasive assessment of autonomic activity for evaluation of pain in calves, using surgical castration as a model. J. Dairy Sci. 93:3602-3609. https://doi.org/10.3168/jds.2010-3114.

Stock, M. L., S. L. Baldridge, D. Griffin, and J. F. Coetzee. 2013. Bovine dehorning: Assessing pain and providing analgesic management. Vet. Clin. North Am. Food Anim. Pract. 29:103-133. https: //doi.org/10.1016/j.cvfa.2012.11.001.

Taddio, A., C. M. McMurtry, V. Shah, R. P. Riddell, C. T. Chambers, M. Noel, N. E. MacDonald, J. Rogers, L. M. Bucci, P. Mousma- nis, E. Lang, S. A. Halperin, S. Bowles, C. Halpert, M. Ipp, G. J. Asmundson, M. J. Rieder, K. Robson, E. Uleryk, M. M. Antony, V. Dubey, A. Hanrahan, D. Lockett, J. Scott, and E. Votta Bleeker. 2015. Reducing pain during vaccine injections: Clinical practice guideline. CMAJ 187:975-982. https://doi.org/10.1503/ cmaj.150391.

Tarvainen, M. P., J.-P. Niskanen, J. A. Lipponen, P. O. Ranta-aho, and P. A. Karjalainen. 2014. Kubios HRV-Heart rate variability analysis software. Comput. Methods Programs Biomed. 113:210 220. https://doi.org/10.1016/j.cmpb.2013.07.024.

Villemure, C., and C. M. Bushnell. 2002. Cognitive modulation of pain: How do attention and emotion influence pain processing? Pain 95:195-199. https://doi.org/10.1016/s0304-3959(02)00007-6.

von Borell, E., J. Langbein, G. Despres, S. Hansen, C. Leterrier, J. Marchant-Forde, R. Marchant-Forde, M. Minero, E. Mohr, A. Prunier, D. Valance, and I. Veissier. 2007. Heart rate variability as a measure of autonomic regulation of cardiac activity for assessing stress and welfare in farm animals - A review. Physiol. Behav. 92:293-316. https://doi.org/10.1016/j.physbeh.2007.01.007.

Weary, D. M., L. Niel, F. C. Flower, and D. Fraser. 2006. Identifying and preventing pain in animals. Appl. Anim. Behav. Sci. 100:6476. https://doi.org/10.1016/j.applanim.2006.04.013.

Wehle, B., M. Bjornstrom, M. Cedgard, K. Danielsson, A. Ekernas, A Gutierrez, U. Petterson, and T. Lindholm. 1989. Repeated application of EMLA cream 5\% for the alleviation of cannulation pain in haemodialysis. Scand. J. Urol. Nephrol. 23:299-302. https://doi .org/10.3109/00365598909180341.

Yarnell, K., C. Hall, and E. Billett. 2013. An assessment of the aversive nature of an animal management procedure (clipping) using behavioral and physiological measures. Physiol. Behav. 118:32-39. https://doi.org/10.1016/j.physbeh.2013.05.013.

Yin, L., and S. Jiang. 2018. Evaluation of EMLA cream for relieving pain during needle insertion on totally implantable venous access device. J. Vasc. Access 19:634-638. https://doi.org/10.1177/ 1129729818768182 . 